\title{
Strontium and Nickel Heterogeneous Catalysts for Biodiesel Production from Macaw Oil
}

\author{
Wiury C. de Abreu, ${ }^{a, b}$ Carla V. R. de Moura, ${ }^{a}$ Jean C. S. Costa ${ }^{c}$ and \\ Edmilson M. de Moura ${ }^{*, a}$ \\ ${ }^{a}$ Departamento de Química, Universidade Federal do Piauí, UFPI, 64049-550 Teresina-PI, Brazil \\ ${ }^{b}$ Instituto Federal do Maranhão, IFMA, 65393-000 Buriticupu-MA, Brazil \\ 'Departamento de Química Fundamental, Instituto de Química, Universidade de São Paulo, USP, \\ 05513-970 São Paulo-SP, Brazil
}

\begin{abstract}
It is presented herein heterogeneous catalysts comprised of strontium and nickel oxides synthesized using a coprecipitation method. They were applied for the preparation of biodiesel from macaw palm oil. The catalysts were characterized by X-ray diffraction (XRD), adsorption and desorption of nitrogen by Brunauer-Emmett-Teller (BET) and Barrett-Joyner-Halenda (BJH) methods, scanning electron microscopy (SEM), Fourier transform infrared spectroscopy (FTIR), and differential thermogravimetric analysis (TG-DTA). The conversion was determined by gas chromatography with flame detector (GC-FID). The best activity was obtained when the catalyst was calcined at $1100{ }^{\circ} \mathrm{C}$ for 3 hours. The highest conversion was reached $(97 \%)$ when the following conditions were used: 5 hours, $2 \%$ of metal loading, $65^{\circ} \mathrm{C}$ and oil/alcohol molar ratio of 1:9.
\end{abstract}

Keywords: heterogeneous catalyst, coprecipitation, biodiesel, macaw oil

\section{Introduction}

The large increase in global petroleum consumption has caused huge environmental impacts and economic issues. In order to provide a future reduction of the world oil dependence, the development of renewable fuels like biodiesel is quite attractive $\mathrm{e}^{1,2}$ since the main advantages of biodiesel include biodegradability, high flash point and low emissions of carbon monoxide and other pollutants. ${ }^{3,4}$ According to Agência Nacional do Petróleo, Gás Natural e Biocombustíveis (ANP) resolution 14/2012 and law number $11.097,{ }^{6}$ which deals with the introduction of sustainable fuel in the Brazilian energy matrix, biodiesel refers to renewable fuels derived from raw materials meant to be used in internal combustion compression ignition engines; they may partially or totally replace fossil feedstock. Usually, these compounds are made by chemically reacting triglyceride molecules present in vegetable oils and animal fats with methanol or ethanol in the presence of a suitable catalyst to form alkyl esters of fatty acids and glicerol. ${ }^{7,8}$

Industrial biodiesel production uses homogeneous alkaline catalysts $\left(\mathrm{KOH}, \mathrm{NaOH}\right.$ and $\left.\mathrm{NaOCH}_{3}\right)$ due to its

*e-mail: mmoura@ufpi.edu.br low cost and high yield of the final products. ${ }^{9-11}$ Although these catalysts are effective, the serious environmental problems they cause has driven the development of more active and selective heterogeneous catalysts lately. ${ }^{12,13}$ The application of heterogeneous catalysts in transesterification reactions is considered a green technology as the catalysts are easily separated from the products and can be recycled. Moreover, the reaction method utilizes less water than the homogeneous catalysts processes..$^{14,15}$ Thus, the development of efficient and low cost heterogeneous catalysts raises the possibility of their commercially utilization on biodiesel production. ${ }^{16}$ Many heterogeneous catalysts have been widely investigated for vegetable oils transesterification such as alkali and alkaline earth metal oxides and transition metal hydroxides compounds supported on alumina, zeolites, hydrotalcites and ion exchange resins. ${ }^{17-22}$

In accordance to Zabeti et al. ${ }^{23}$ strontium oxide has specific surface area of $1.05 \mathrm{~m}^{2} \mathrm{~g}^{-1}$, alkaline characteristics and high activity in the reaction medium. However, it is not widely used for the transesterification reaction. On the other hand, the nickel oxide has received considerable attention due to its high surface area, low production costs and possible porous nature. ${ }^{15,24}$ Therefore, mixed metal 
oxides has emerged as good heterogeneous catalysts for transesterification reaction as they provide a better alkalinity and specific area, achieving high activity and stability. ${ }^{16}$ Different mixed metal oxides are used as catalysts in transesterification reactions as $\mathrm{CaZnO}$, $\mathrm{CaMgO}, \mathrm{CaO}-\mathrm{MgO}, \mathrm{Cr}_{2} \mathrm{O}_{3} / \mathrm{Na}_{2} \mathrm{CrO}_{4} / \mathrm{Al}_{2} \mathrm{O}_{3}, \mathrm{TiO}_{2}-\mathrm{MgO}$ and $\mathrm{NaZrO}_{3} \cdot{ }^{25-27}$

The development of strontium and nickel based heterogeneous catalysts is promising as strontium oxide exhibits a high catalytic activity in the transesterification reaction and may present a synergy with nickel oxide providing a superior durability and a higher activity. Thereby, this study was designed to investigate the synthesis and characterization of strontium and nickel-based catalysts for transesterification reaction of macaw palm oil (Acrocomia aculeata). The optimization of the reaction parameters, homogeneity test and reuse of the catalysts were conducted with the catalyst that presented the best catalytic activity.

\section{Experimental}

All reagents were commercially available and used without further purification, except when specified. The reagents used were: nickel(II) nitrate hexahydrate (P.A., Impex), acetone (P.A., Dinamica), strontium nitrate (P.A., Impex), ammonia carbonate (P.A., Impex), phosphoric acid (85\% P.A., Dynamic), methyl alcohol (P.A., Impex), anhydrous sodium sulfate (Dynamics) and deionized water. Macaw palm oil was purchased in local shops (Teresina City, Piauí, Brazil) and was degummed with phosphoric acid following the procedure described by Morais et al. ${ }^{28}$ prior utilization. The chemical and physical properties of macaw palm oil are listed in Table 1.

Table 1. Physical and chemical properties of the macaw oil

\begin{tabular}{lc}
\hline Property & Value \\
\hline Caprilic acid (C08:0) / (wt.\%) & 5.15 \\
Capric acid (C10:0) / (wt.\%) & 6.63 \\
Lauric acid (12:0) / (wt.\%) & 33.32 \\
Miristic acid (C14:0) / (wt.\%) & 16.34 \\
Palmitic acid (C16:0) / (wt.\%) & 10.78 \\
Stearic acid (C18:0) / (wt.\%) & 5.53 \\
Oleic acid (C18:1) / (wt.\%) & 19.11 \\
Linoleic acid (C18:2) / (wt.\%) & 3.14 \\
Molar mass average / (g mol $\left.{ }^{-1}\right)$ & 725.05 \\
Acid index / (mg KOH g-1) & 0.61 \\
Kinematic viscosity / $\left(\mathrm{mm}^{2} \mathrm{~s}^{-1}\right)$ & 27.5 \\
Density at $20{ }^{\circ} \mathrm{C} /\left(\mathrm{g} \mathrm{cm}^{-1}\right)$ & 920 \\
\hline
\end{tabular}

\section{Catalysts preparation}

For the catalyst preparation, $250 \mathrm{~mL}$ of strontium nitrate $\left(0.33 \mathrm{~mol} \mathrm{~L}^{-1}\right)$ and $250 \mathrm{~mL}$ of nickel(II) nitrate hexahydrate $\left(0.33 \mathrm{~mol} \mathrm{~L}^{-1}\right)$ were mixed and stirred for 30 minutes. The solution was adjusted to $\mathrm{pH} 8$ by addition of an aqueous solution of ammonium carbonate $\left(0.33 \mathrm{~mol} \mathrm{~L}^{-1}\right)$ and centrifuged at 3,500 rpm. The solid formed was washed with deionized water and ketone several times and the material was dried in air and then calcined at different temperatures and times, as presented in Table 2.

Table 2. Preparation conditions of the catalysts

\begin{tabular}{lccc}
\hline Name of catalyst & $\begin{array}{c}\text { Molar ratio } \\
\text { Sr:Ni }\end{array}$ & $\begin{array}{c}\text { Calcination } \\
\text { temperature } /{ }^{\circ} \mathrm{C}\end{array}$ & $\begin{array}{c}\text { Calcination } \\
\text { time / h }\end{array}$ \\
\hline W1 & & 1000 & 2 \\
W2 & $1: 1$ & & 3 \\
W3 & & 1100 & 4 \\
W4 & & & 2 \\
W5 & & 3 \\
W6 & & & 4 \\
\hline
\end{tabular}

\section{Transesterification reaction}

The transesterification reaction was performed using different experimental conditions. The modifications include oil/alcohol molar ratio, amount of catalyst and reaction time (Figure 1), as specified for each reaction. For all the experiments carried out, the catalyst and methanol were placed at a two-neck round-bottom flask connected to a condenser. After a 30-minute stirring at room temperature, the macaw palm oil was added into the glassware and the temperature was raised to $65^{\circ} \mathrm{C}$ and kept for 4 hours under stirring. The mixture was centrifuged at 3,500 rpm to allow

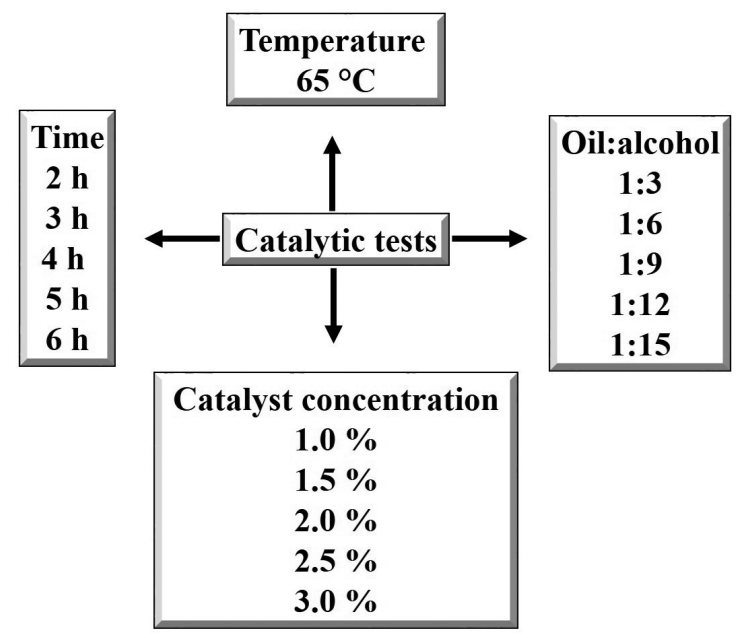

Figure 1. Experimental design for transesterification reactions. 
the catalyst separation. The methanol was removed using a rotatory evaporator, the products were separated in a separatory funnel, and the lower phase (glycerol) discarded. The ester obtained was washed three times with hot water $\left(80^{\circ} \mathrm{C}\right)$ and dried using sodium sulfate. The biodiesel was stored for further characterization.

The catalysts used for these reactions were chosen among five materials synthesized (W1, W2, W3, W4 and W5); they were used under the same experimental apparatus described earlier using the same conditions, which made possible a comparison. The experimental conditions were: 15,1 and $50 \mathrm{~g}$ of alcohol, catalyst and macaw palm oil, respectively. After this step, the best catalyst was selected.

Heterogeneity and reusability of catalyst

To study the heterogeneity and reusability of the catalysts, the following experimental conditions were used: 5 hours, $2 \%$ of metal loading, $65^{\circ} \mathrm{C}$ and oil/alcohol molar ratio of $1: 9$.

To guarantee the heterogeneity of the proposed system, the catalyst was mixed with methanol and maintained under vigorous magnetic stirring for 30 minutes. Then, the solid was removed by centrifugation at 3,500 rpm for 20 minutes and the residual methanol was added to macaw oil and the same reaction conditions were reproduced. The content of methyl esters in the biodiesel was determined from gas chromatography with flame detector (GC-FID) analysis.

For the recycling experiments, after each transesterification reaction, the catalyst was filtrated and washed with petroleum and methanol ether to remove the organic residues (oil and/or glycerol) present on the surface of the catalyst. Then, the material was warmed to $120{ }^{\circ} \mathrm{C}$ for $24 \mathrm{~h}$ and calcined at $1100{ }^{\circ} \mathrm{C}$ for 3 hours for activation. After this procedure, the solid was reused in sequential transesterification reactions.

\section{Instrumentation}

Fourier transform infrared spectroscopy (FTIR) spectra were measured on a PerkinElmer Spectrum 100 Spectrometer after 16 scans. Spectra were stored in the range of $4000-400 \mathrm{~cm}^{-1}$ and the samples were analyzed using the technique of $\mathrm{KBr}$ pastilles $(1: 100 \mathrm{mg})$. Thermogravimetric analyses (TG) were conducted in a simultaneous thermobalance TG-DTG, Shimadzu ${ }^{\circledR}$ DTG-60. The temperature range used for each analysis was 30-1000 ${ }^{\circ} \mathrm{C}$ under a nitrogen flow of $50 \mathrm{~mL} \mathrm{~min}{ }^{-1}$ using a platinum pan. Powder X-ray diffraction (XRD) patterns were carried out in a Shimadzu LabX XRD-6000 model equipped with a Rigaku rotating anode (ROTAFLEX) diffractometer operating at $30 \mathrm{kV}$ and $15 \mathrm{~mA}$ with a monochromatic $\mathrm{Cu} K \alpha$ radiation $(\lambda=1.54 \AA)$ and a graphite monochromator. Samples were scanned from 10 to 90 degrees $(2 \theta)$ at 0.05 degree intervals at a rate of 1.5 degree $\mathrm{min}^{-1}$. The diffractograms were analyzed and compared with JCPDS-ICDD cards (Joint Committee on Powder Diffraction Standards-International Center for Diffraction Data) available on the Crystallographic Search Match software (plug: 014 191). The textural characteristics, such as Brunauer-Emmett-Teller (BET) specific area, pore volume and average pore diameter (Barrett-Joyner-Halenda, BJH) were determined by $\mathrm{N}_{2}$ adsorption-desorption at $77 \mathrm{~K}$ in an ASAP2010 apparatus (Micromeritics, Norcross, GA, USA). Shimadzu microscope, SSX-550 Superscan model, was used to determine the average size, particle morphology and composition of the catalysts. The samples were fractured in liquid nitrogen to prevent their plastic deformation then placed in a carbon tape and coated with a thin layer of gold (sputtering, ion coater IC-50, Shimadzu, using a current of $4 \mathrm{~mA}$ ).

The alkalinity of the catalysts was determined by volumetric analyses using a standard solution of potassium biphthalate acid $\left(0.1 \mathrm{~mol} \mathrm{~L}^{-1}\right)$ and phenolphthalein as indicator. The alkalinity of the catalyst was calculated dividing the number of moles of biphthalate consumed by the mass of the catalyst used. The density of alkali active sites were determined from the alkalinity values and areas of the catalysts, in accordance to equation $1 .{ }^{29}$

No. of active sites alkalinity $=\frac{\text { basicity }}{\text { catalyst area }}$

The content of fatty acid methyl esters (FAMEs) was determined from GC-FID analyses wherein the samples were prepared by adding exactly $50 \mathrm{mg}$ of the BIOCRAL (0.2 $\mathrm{mL}$ of methyl heptadecanoate solution in heptane, $5.08 \mathrm{mg} \mathrm{mL}^{-1}$ ) as the internal standard. The equipment used to analyze the FAMEs was a QP 2010 GC-FID Shimadzu, equipped with a capillary column (DB-5HT, $0.32 \mathrm{~mm}$, $30 \mathrm{~m}, 0.1 \mu \mathrm{m}$ film thickness). Samples were injected at $70{ }^{\circ} \mathrm{C}$ and maintained in this temperature for one minute. In a typical run, the column temperature was ramped up from the initial 70 to $190{ }^{\circ} \mathrm{C}$ at a rate of $15^{\circ} \mathrm{C} \mathrm{min}^{-1}$, to $260{ }^{\circ} \mathrm{C}$ at $7{ }^{\circ} \mathrm{C} \mathrm{min}-1$ and to $380{ }^{\circ} \mathrm{C}$ at $20^{\circ} \mathrm{C} \mathrm{min}{ }^{-1}$ and kept at the final temperature for 10 minutes. The carrier gas used was nitrogen. The temperature of the injector and detector were both set at $380{ }^{\circ} \mathrm{C}$. The sample injection volume was $1 \mu \mathrm{L}$ and the reagent and product identifications were attributed to the characteristic GC-FID retention times of the sample and the standard compounds. 
The ester content was determined by GC-FID using the procedure described at EN 14103:2003, ${ }^{30}$ obtained by integrating the peak areas in the range of $\mathrm{C} 8: 0$ to $\mathrm{C} 18: 0$ and subtracting the area of methyl heptadecanoate (C17:0), according to equation 2 .

$\mathrm{C}=\frac{\left(\sum \mathrm{A}\right)-\mathrm{A}_{\mathrm{EI}}}{\mathrm{A}_{\mathrm{EI}}} \times \frac{\mathrm{C}_{\mathrm{EI}} \times \mathrm{V}_{\mathrm{EI}}}{\mathrm{m}} \times 100 \%$

where $\Sigma \mathrm{A}=$ total peak area of ethyl esters comprising the range of $\mathrm{C} 8: 0$ to $\mathrm{C} 18: 0 ; \mathrm{A}_{\mathrm{EI}}=$ area of methyl heptadecanoate $(\mathrm{C} 17: 0) ; \mathrm{C}_{\mathrm{EI}}=$ concentration of the $\mathrm{C} 17: 0$ solution $\left(\mathrm{mg} \mathrm{mL}^{-1}\right) ; \mathrm{V}_{\mathrm{EI}}=$ volume $(\mathrm{mL})$ of the $\mathrm{C} 17: 0$ solution added in the sample; $\mathrm{m}=$ weight $(\mathrm{mg})$ of the sample.

\section{Results and Discussion}

This study deals with the preparation and characterization of a new oxide mixture of strontium and nickel to produce biodiesel. We obtained a new compound with different characteristics from those described in literature. ${ }^{15,23,24}$ To the best of our knowledge, many mixtures of strontium oxides were reported, however any mixture with strontium and nickel oxides were studied on transesterification reactions of vegetable oils.

\section{Catalysts characterization}

Figure 2 shows the TG data of the mixture of strontium/ nickel carbonate before calcination. The figure displays three main weight loss regions. The first weight loss (10\%) in the $50-150{ }^{\circ} \mathrm{C}$ region may be due to dehydration and decomposition of volatile compounds. The second one presents a loss of $13 \%$ between $170-500{ }^{\circ} \mathrm{C}$, related to decomposition of carbonate, and the third weight loss (18\%) resulted from the oxide formation and occurs in the 760-900 ${ }^{\circ} \mathrm{C}$ region.

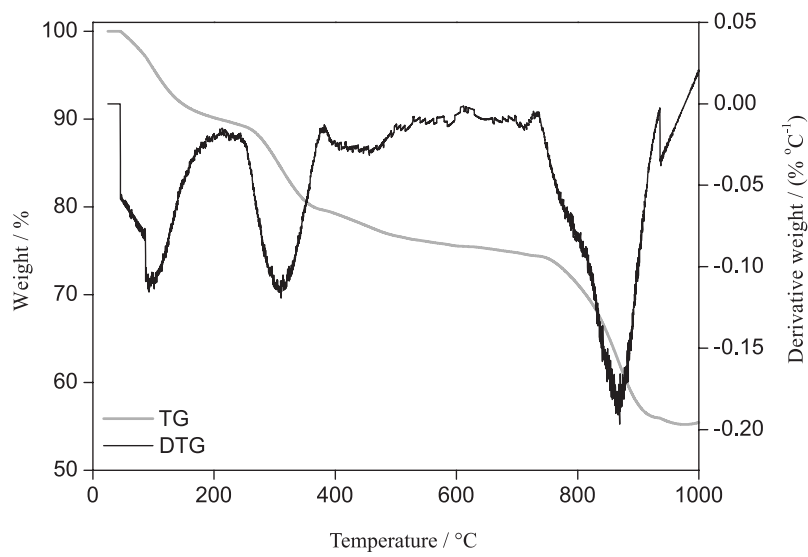

Figure 2. Thermogravimetry curves of the catalyst precursors.
Figure 3 shows the XRD of W1, W2, W3, W4 and W5. In all cases, the diffraction pattern was indexed to the crystalline phases of $\mathrm{NiO}$ and $\mathrm{SrO}$. The peaks in $2 \theta=19.26$, $37.47,43.33,50.33,62.91,75.60$ and $79.54^{\circ}$ correspond to monoclinic structure of $\mathrm{NiO}$ in accordance to JCPDS 656920 crystallographic card. ${ }^{31}$ Peaks in $2 \theta=31.60,37.63$ and $52.17^{\circ}$ were observed in agreement to JCPDS 27-1304 card, ${ }^{32}$ corresponding to tetragonal structure of SrO. The other peaks observed on the diffractogram are related to the precursors and undesired materials as hydroxides and carbonates. Initially, the catalysts' diffractograms show the presence of $\mathrm{NiO}$, however increasing the calcination time and temperature, the peaks intensity are enhanced. Furthermore, when the temperature is increased, the peaks corresponding to $\mathrm{NiO}$ structure are intensified.

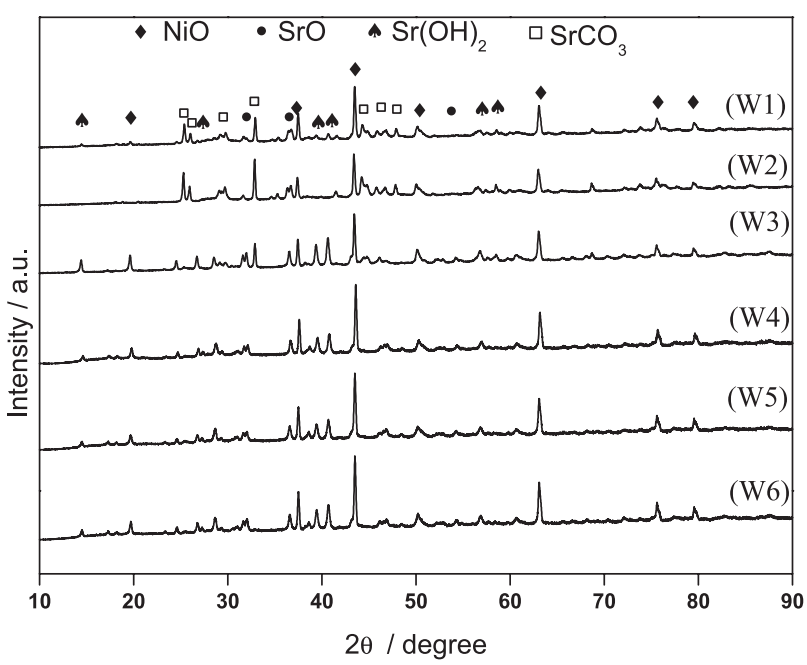

Figure 3. Diffractograms of: $\mathrm{W} 1\left(1000{ }^{\circ} \mathrm{C}\right.$ by 2 hours); W2 $\left(1000{ }^{\circ} \mathrm{C}\right.$ by 3 hours); W3 (1000 ${ }^{\circ} \mathrm{C}$ by 4 hours); W4 $\left(1100^{\circ} \mathrm{C}\right.$ by 2 hours); W5 $\left(1100{ }^{\circ} \mathrm{C}\right.$ by 3 hours) and $\mathrm{W} 6\left(1100^{\circ} \mathrm{C}\right.$ by 4 hours $)$.

The most important factor is the temperature eventually, as W5 and W6 catalysts do not show a significant intensity increase of $\mathrm{NiO}$ when compared with the catalyst W4. The presence of $\mathrm{SrO}$ is enhanced in the catalyst W2. The temperature and time have an influence also in this case, however the peaks are not as intense as to $\mathrm{NiO}$ ones, due to this crystalline compound formation. The presence of $\mathrm{SrCO}_{3}$ may be noticed in $\mathrm{W} 1$ catalyst, due to the peaks in $2 \theta=25.38,26.02,29.76,32.80,44.30,45.96,46.80$ and $48.05^{\circ}$, according to JCPDS 52-1526 card..$^{33}$ These peaks are observed in the diffractograms of the other catalysts, however the peaks intensity are decreased with calcination time and temperature increasing, leading to the formation of oxides.

The diffraction peaks at $2 \theta=14.36,28.49,38.45$, $39.29,56.66$ and $58.65^{\circ}$ (JCPDS 19-1267) (J4 $^{34}$ show the presence of strontium hydroxide in the catalysts. L'vov ${ }^{35}$ reported a similar result and attributed this peak to 
carbonate decomposition, a parallel reaction between water and carbonate that produces hydroxides and $\mathrm{CO}_{2}$. For the catalysts synthesized, hydroxide has no major effect because of its low intensity, although some water content may be observed.

The FTIR results of the catalysts showed that increasing calcination temperature and time, there was a significant intensity decrease of bands 1480 and $900 \mathrm{~cm}^{-1}$; these bands are attributed to the stretching of carbon and oxygen bonds of $\mathrm{CO}_{3}{ }^{2-}$ ions present in $\mathrm{SrCO}_{3}$. The stretching bands in the region $3600-3000 \mathrm{~cm}^{-1}$ are assigned to the $\mathrm{OH}$ group of $\mathrm{Sr}(\mathrm{OH})_{2}$. These results are corroborated by data from XDR analysis. ${ }^{7}$ The FTIR shows bands in 600 and $460 \mathrm{~cm}^{-1}$ which may be attributed to the stretching of $\mathrm{Sr}-\mathrm{O}$ and $\mathrm{Ni}-\mathrm{O}$ bonds, respectively, indicating the formation of strontium oxide and nickel oxide. ${ }^{36-38}$

The results of the specific surface area $\left(\mathrm{ASS}_{\mathrm{BET}}\right)$, average pore diameter and average pore volume for the catalysts synthesized are listed in Table 3. Correlating the results of specific surface area, with those described by Carvalho et al. ${ }^{15}$ and Nascimento et al., ${ }^{39}$ for $\mathrm{SrO}$ $\left(2.02 \mathrm{~m}^{2} \mathrm{~g}^{-1}\right)$ and $\mathrm{NiO}\left(6.44 \mathrm{~m}^{2} \mathrm{~g}^{-1}\right)$, respectively, we may believe that after interactions between $\mathrm{NiO}$ and $\mathrm{SrO}$, a new compound was formed presenting an intermediate surface area of the other two. This hypothesis is in agreement with the lowest value found for the catalyst W1 $\left(2.84 \mathrm{~m}^{2} \mathrm{~g}^{-1}\right)$ and the highest value found for the calcined catalyst W3 $\left(5.60 \mathrm{~m}^{2} \mathrm{~g}^{-1}\right)$. According to IUPAC, ${ }^{40}$ mesoporous materials have pore diameters between 20 and $500 \AA$, so the synthesized catalysts have mesoporous structure.

Table 3 shows that W1 and W4 catalysts have the higher density alkaline sites among the catalysts; however, these values may be related to the presence of strontium carbonate as shown in XRD. The other samples synthesized also exhibit an alkali profile, which is a good result as well, because, as Abbaszaadeh et al. ${ }^{41}$ reported, solid alkaline catalysts may exhibit better catalytic activity compared with other catalysts, due to its activation close to the boiling point temperature of methanol, improving the biodiesel production and reducing its commercial value.
Figure 4 shows SEM images of the catalysts in which the presence of particle-shaped agglomerates of irregular rods with different sizes can be observed. This clustering promotes a decreasing in the surface area, as the results showed in $\mathrm{ASS}_{\mathrm{BET}}$. The micrographs have different particle sizes, as shown in Figure 5; the catalyst W1 showed the larger size $(1.47 \pm 0.2 \mu \mathrm{m})$, which may be associated to the presence of residual carbonate. Observing the particle size of the catalyst calcined W5 $(1.05 \pm 0.09 \mu \mathrm{m})$ and its size distribution, it is possible to realize that the particles' size is more homogeneous than the orders catalysts, however the particles of W6 catalyst suffered some degree of agglomeration and increase in size $(1.23 \pm 0.09 \mu \mathrm{m})$, probably related to overheating.

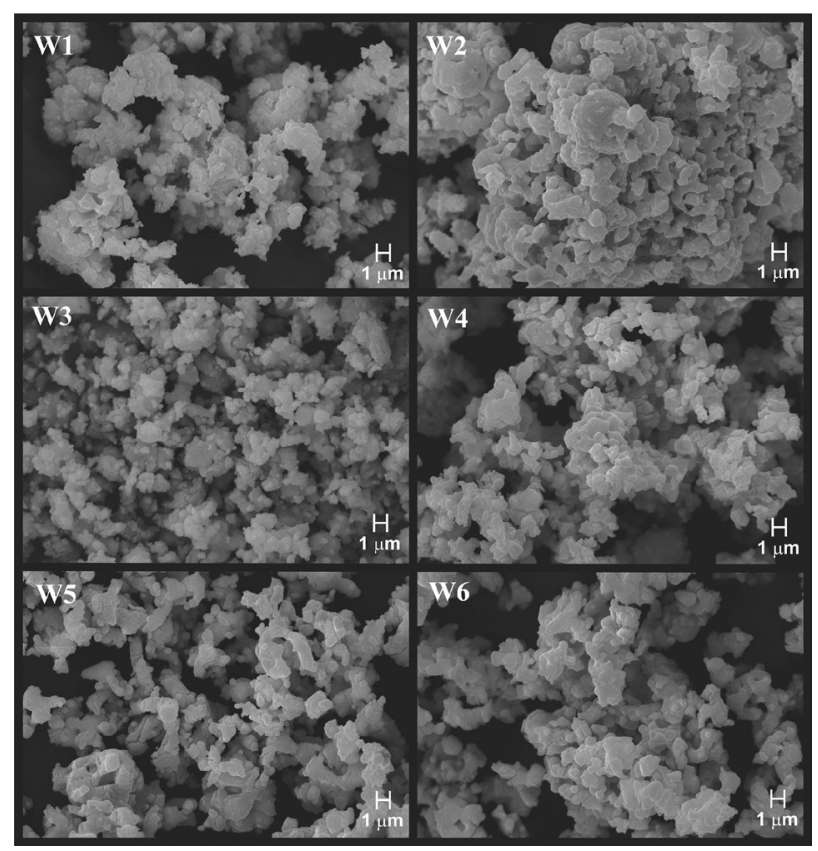

Figure 4. SEM images of the catalysts: W1; W2; W3; W4; W5 and W6.

\section{Catalytic tests}

The six compounds (W1, W2, W3, W4, W5, and W6) were tested in transesterification reactions using macaw

Table 3. Results of nitrogen adsorption analysis

\begin{tabular}{lccccc}
\hline Catalyst & $\mathrm{ASS}_{\mathrm{BET}} /\left(\mathrm{m}^{2} \mathrm{~g}^{-1}\right)$ & $\mathrm{d}_{\text {pores }} / \AA$ & $\mathrm{V}_{\text {pores }} /\left(\mathrm{cm}^{3} \mathrm{~g}^{-1}\right)$ & Alkalinity / $\left(\mathrm{mol} \mathrm{g}^{-1}\right)$ & Density of alkali sites / (mol $\left.\mathrm{m}^{2}\right)$ \\
\hline W1 & 2.84 & 41.7 & 0.003 & 0.0107 & 0.00376 \\
W2 & 5.51 & 67.3 & 0.009 & 0.0108 & 0.00196 \\
W3 & 5.60 & 72.0 & 0.010 & 0.0103 & 0.00184 \\
W4 & 2.57 & 25.0 & 0.006 & 0.0105 & 0.00408 \\
W5 & 4.62 & 84.0 & 0.010 & 0.0106 & 0.00230 \\
W6 & 3.14 & 62.0 & 0.005 & 0.0101 & 0.00322 \\
\hline
\end{tabular}

$\mathrm{ASS}_{\mathrm{BET}}$ : specific surface area; dpores: BJH desorption average pore diameter; $\mathrm{V}_{\text {pores }}: \mathrm{BJH}$ desorption cumulative pore volume. 


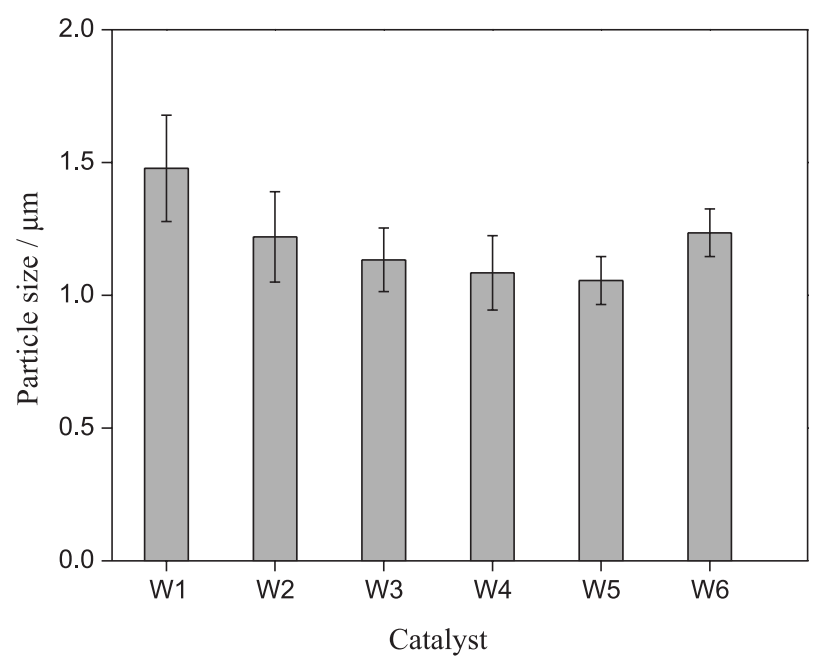

Figure 5. Particle size of the catalysts: W1, W2, W3, W4, W5 and W6.

palm oil and methanol. The yields obtained are plotted in Figure 6 . The catalysts synthesized at $1000^{\circ} \mathrm{C}$ for two and three hours (W1 and W2) did not show enough activity. The catalyst W3 showed a yield of $41 \%$, which is a reasonable result; however compared to the catalysts synthesized at $1100{ }^{\circ} \mathrm{C}$, it is not good enough. The catalysts $\mathrm{W} 4$, W5 and W6, showed conversion above $78 \%$. Correlating the results with the XRD patterns shown in Figure 3, it is evident that the active phase for the transesterification reaction is related to $\mathrm{NiO}$ and $\mathrm{SrO}$, and the carbonate is inactive to this reaction as the oxides which have higher levels of carbonate failed in the catalysis tests.

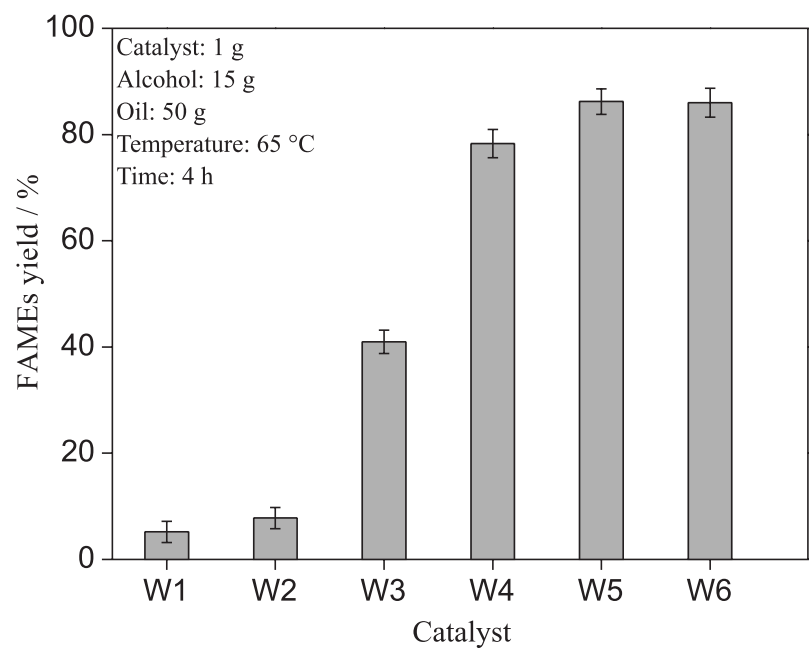

Figure 6. Catalytic activity of catalysts W1, W2, W3, W4, W5 and W6 in trasesterification reactions of macaw oil with methanol to produce biodisel.

\section{Optimization of reaction parameters}

After the catalytic tests, it was observed that the catalyst which presented a better performance with a lower synthesis cost was the one calcined at $1100{ }^{\circ} \mathrm{C}$ for
3 hours (W5). According to Ramadhas et al. ${ }^{42}$ and Koh and $\mathrm{Ghazi}^{43}$ the transesterification process and conversion into to ester may be affected for the oil/alcohol molar ratio, time, concentration of catalyst into the medium, temperature, etc. Thus, reaction optimization parameters for the transesterification reaction of macaw palm oil with methyl alcohol were made using the catalyst W5. The catalyst concentration was examined by fixing the oil/alcohol molar ratio in $1: 9$, the reaction time in 4 hours, and the temperature in $65{ }^{\circ} \mathrm{C}$. Figure 7 shows the relationship between the catalyst concentration used and the conversions. The results showed that the conversion increased when the catalyst concentration increased, reaching $86.3 \%$ of conversion, the highest one, using a catalyst concentration of $2.0 \% \mathrm{~m} / \mathrm{m}$ to the amount of oil used in the reaction. Catalyst concentrations higher than $2.0 \%$ decrease the conversion of biodiesel, probably due to the poor diffusion of alcohol, catalyst and oil.

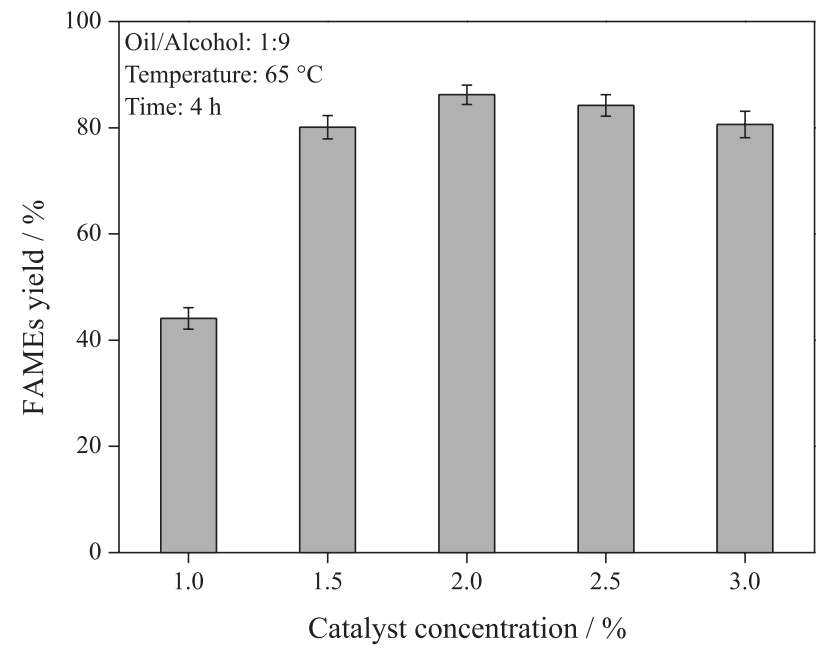

Figure 7. Effect of catalyst W5 usage on FAMEs yield in concentrations of $1.0,1.5,2.0,2.5$ and $3.0 \%$.

The effect of the oil/alcohol molar ratio in the transesterification reaction was investigated by setting the concentration of catalyst $\mathrm{W} 5$ in $2.0 \%$, temperature in $65{ }^{\circ} \mathrm{C}$ and reaction time in 4 hours. Figure 8 shows the relationship between the oil/alcohol molar ratios and the yield of biodiesel.

The stoichiometric oil/alcohol molar ratio required to complete the transesterification reaction is 3 , but it is not sufficient to complete the reaction due to the reversibility of the reaction, thus a higher molar ratio is required to drive the completion of the reaction. ${ }^{44}$ Therefore, the oil/ethanol molar ratio of 1:3 showed low conversion into biodiesel; however, the molar ratio of 1:9 was the best one. In this case, the conversion reached $86.2 \%$ and, according to Figure 8, above this molar ratio there is a gradual decrease in the 


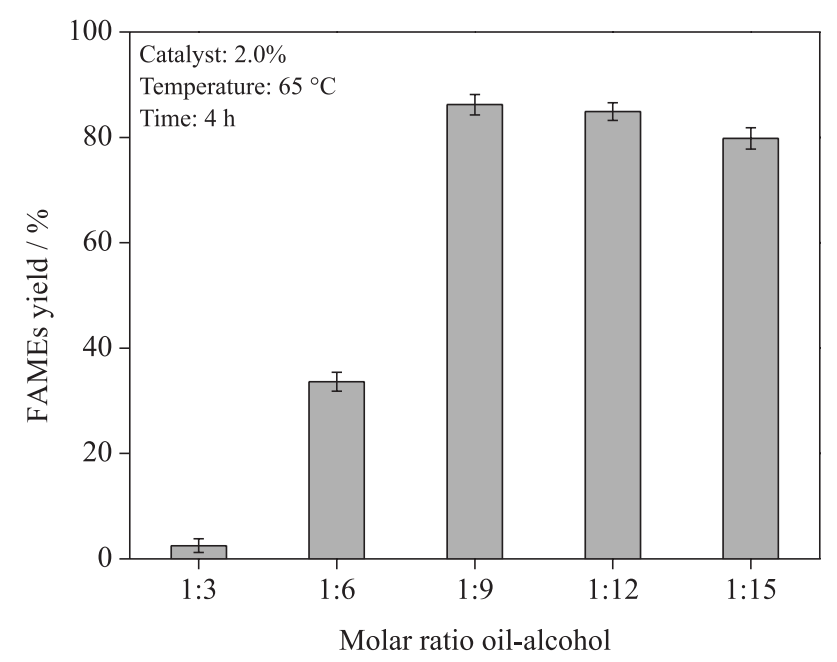

Figure 8. Effect of the oil/alcohol molar ratio (1:3, 1:6, 1:9, 1:12 and 1:15) on FAMEs yield.

conversion of the triglycerides. The reaction time factor was also investigated by setting the concentration of catalyst W5 in $2.0 \% \mathrm{~m} / \mathrm{m}$ according to the oil, oil/alcohol molar ratio $1: 9$ and temperature of $65^{\circ} \mathrm{C}$. Figure 9 shows the relationship between the reaction time and the yield of biodiesel.

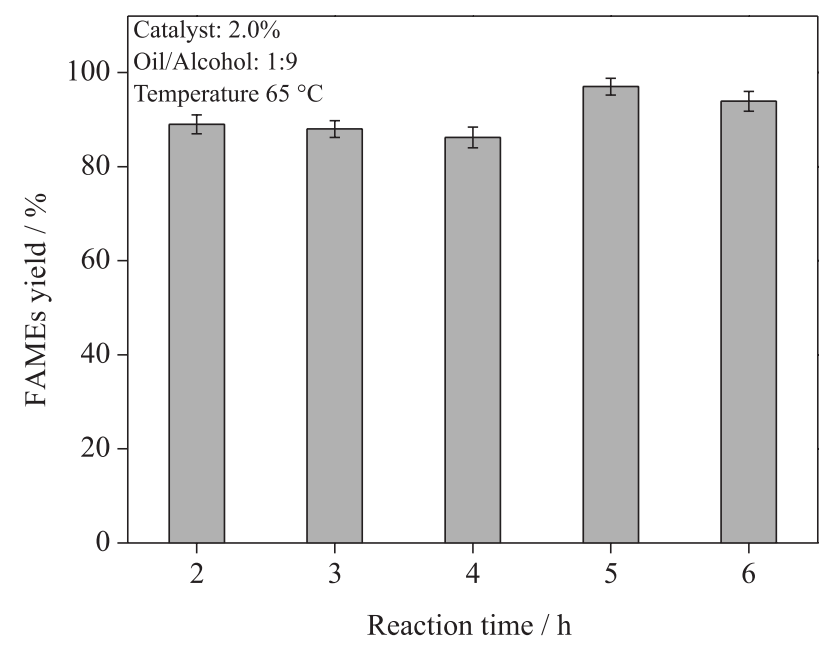

Figure 9. Effect of reaction time (2, 3, 4, 5 and $6 \mathrm{~h})$ on the FAMEs yield.

The results showed that the best reaction time is 5 hours, reaching a conversion of $97 \%$. A longer reaction time decreases the yield for the reaction, as seen in reaction time of 6 hours. The conversion decreases because of the hydrolysis of esters (transesterification reverse reaction) and the formation of soap from residuals fatty acids..$^{45}$ These results are quite interesting when compared with catalysts synthesized with $\mathrm{NiO}$. This compound does not present catalytic activity for the reaction, unless it is supported in some oxide materials. When supported on SBA- 15 or $\mathrm{Al}_{2} \mathrm{O}_{3}$, the yields were 40 and $89 \%$, respectively. The catalyst W5 presents high activities in one synthesis one-pot. ${ }^{46,47}$

\section{Homogeneous contribution}

The homogeneity test of the W5 catalyst showed the predominant heterogeneity of the system because, after removal of the catalyst of the medium, the reaction hardly occurs. It means that the conversion rates obtained for the reaction product after removing the catalyst was approximately $2.0 \%$, similar to the observed when the reaction is carried out only with alcohol and oil, without addition of catalyst. Thus, it may be suggested that $98.0 \%$ of the catalytic activity observed in the reactions monitored in this study is attributed to the heterogeneous character of the catalyst.

\section{Reusability of catalyst}

Recycling is an important feature for the production of a heterogeneous catalyst to be commercially viable. Studies of reuses were made using the best parameters found in the transesterification reaction (catalyst concentration of $2.0 \%$, oil/alcohol molar ratio 1:9, temperature and reaction time equal to $65^{\circ} \mathrm{C}$ and 5 hours, respectively) and the results are shown in Figure 10. Analyzing the results, it is possible to observe that the biodiesel conversion gradually decreases until the $3^{\text {rd }}$ reaction, however keep conversions higher than $84 \%$. The $4^{\text {th }}$ and $5^{\text {th }}$ catalytic cycle are still quite satisfactory, presenting conversions higher than $67.0 \%$.

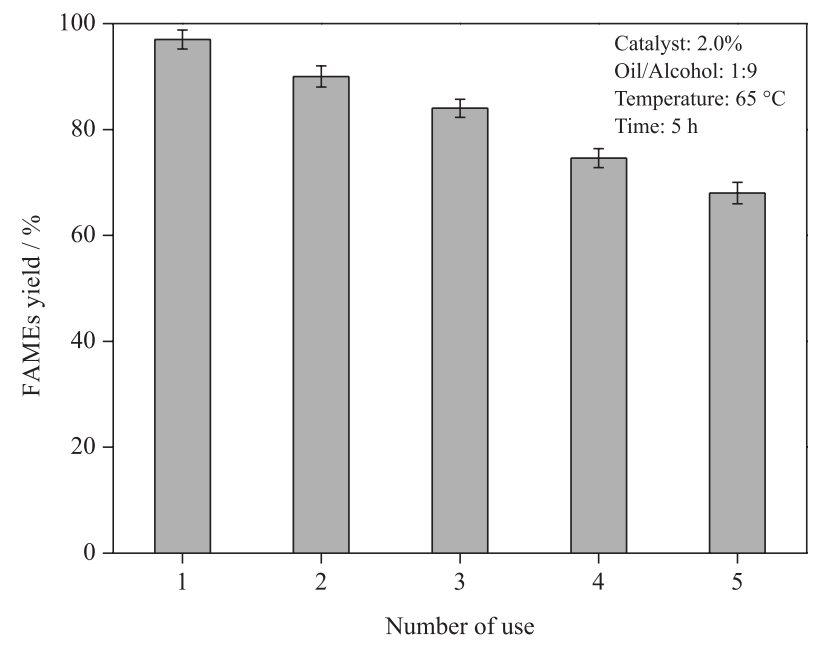

Figure 10. Effect of the catalyst recycling on the FAMEs yield.

In order to study the gradually decreasing activity of the W5 catalyst on recycling reactions, XRD analyses were performed with the fresh (as prepared-W5.1) catalyst and after the second (W5.3) and the fourth (W5.5) reactions (Figure 11). The catalyst W5.1 shows diffraction peaks related to $\mathrm{NiO}$ and $\mathrm{SrO}$, indicating that the first application of the catalyst exhibits catalytic contribution of both oxides. 


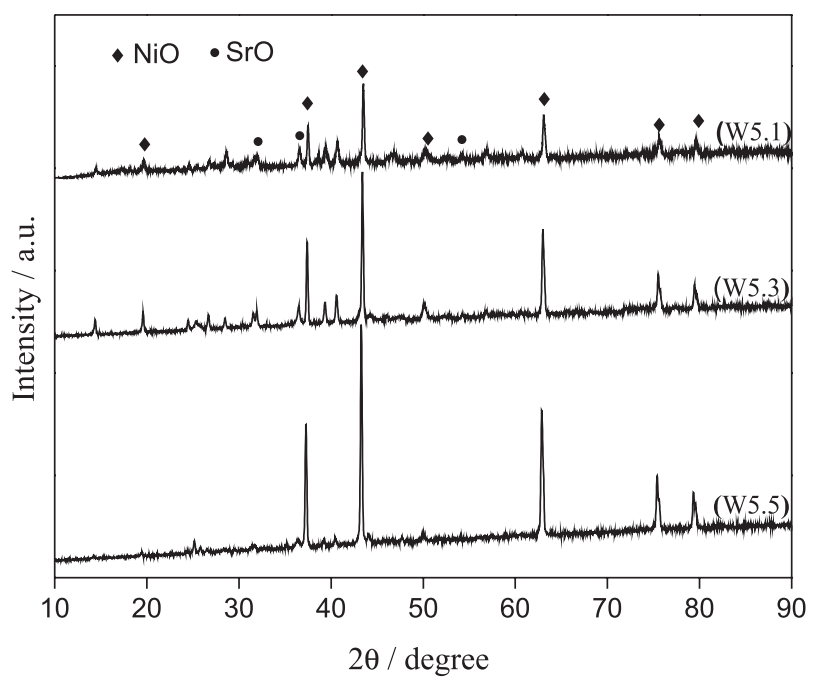

Figure 11. Diffractograms of catalysts: W5.1 (fresh catalyst); W5.3 (before cycle 3); W5.5 (before cycle 5).

The XRD pattern of the sample W5.3 presents a decreasing in the intensity of the characteristic peak of $\mathrm{SrO}$ when compared to the diffractogram of the sample W5.1. The decrease is more evident in the sample W5.5, which has practically no $\mathrm{SrO}$ characteristic peaks. It is also observed an intensity increase of the characteristic peaks of $\mathrm{NiO}$ due to the presence of higher nickel oxide crystals that are formed by smaller nickel particles that agglomerates after several heating treatments. Thus, we suggest that the loss of catalytic activity in the recycling process is associated with the reducing amount of $\mathrm{SrO}$ in the catalyst, which probably leached during the recycling reactions, and also by the agglomeration of the nickel crystals, thereby decreasing the number of active sites.

\section{Conclusions}

Analyzes performed in this study showed that the synthesized catalysts are a mixture of strontium and nickel oxide; we also realized that the increase in calcination temperature and time leads to the formation of oxides and decomposition of undesired materials. The catalysts have different sizes and surface areas, and these characteristics are responsible for the different reaction yields. The catalytic tests present good yields for the catalysts calcined at $1100{ }^{\circ} \mathrm{C}$. The one that showed the best results in terms of ester conversion was the catalyst calcined at $1100{ }^{\circ} \mathrm{C}$ for 3 hours. The transesterification reaction with the catalyst calcined at $1100{ }^{\circ} \mathrm{C}$ for $3 \mathrm{~h}$ was optimized and biodiesel obtained showed yield of $97 \%$ under the conditions of catalyst concentration of $2.0 \%$, oil/alcohol molar ratio of $1: 9$, temperature of $65{ }^{\circ} \mathrm{C}$ and reaction time of 5 hours. The study of homogeneity of the catalyst showed that it is predominantly heterogeneous. The recycling tests showed that the yield decreases, however the activities obtained are still very high even in $5^{\text {th }}$ reaction, reaching $67 \%$ of conversion.

\section{Acknowledgments}

The authors thank the financial support of CAPES and CNPq, the technical support of Center for Strategic Technology of the Northeast (CETENE-PE) and Marco Aurélio Sueller Garcia for his valuable collaboration.

\section{References}

1. Marchetti, J. M.; Miguel, V. U.; Errazu, A. F.; Renewable Sustainable Energy Rev. 2007, 11, 1300.

2. Baskar, G.; Aiswarya, R.; Renewable Sustainable Energy Rev. 2016, 57,496

3. Talebian-Kiakalaieh, A.; Amin, N. A. S.; Mazaheri, H.; Appl. Energy 2013, 104, 683.

4. Halim, R.; Danquah, M. K.; Webley, P. A.; Biotechnol. Adv. 2012, 30, 709 .

5. Agência Nacional do Petróleo, Gás Natural e Biocombustíveis (ANP); Resolução ANP No. 14 de 11 de Junho de 2012, Publicação no Diário Oficial da União de 18/06/2012.

6. Agência Nacional do Petróleo, Gás Natural e Biocombustíveis (ANP); Lei No. 11.097, Dispõe sobre a Introdução do Biodiesel na Matriz Energética Brasileira, de 13 de Janeiro de 2013, Publicação no Diário Oficial da União de 14/01/2005.

7. Pasupulety, N.; Gunda, K.; Liu, Y.; Rempel, G. L.; Ng, F. T. T.; Appl. Catal., A 2013, 452, 189.

8. Graboski, M. S.; Mccormick, R. L.; Prog. Energy Combust. Sci. 1998, 24, 125.

9. Reinoso, D. M.; Damiani, D. E.; Tonetto, G. M.; Appl. Catal., A 2012, 449, 88

10. Lima, J. R. O.; Silva, R. B.; Silva, C. C.; Santos, L. S. S.; Santos Jr., J. R.; Moura, E. M.; Moura, C. V. R.; Quim. Nova 2007, 30, 600.

11. Santori, G.; Nicola, G. D.; Moglie, M.; Palonara, F.; Appl. Energy 2012, 92, 109.

12. Alhassan, F. H.; Yunus, R.; Rashid, U.; Sirat, K.; Islam, A.; Lee, H. V.; Taufiq-Yap, Y. H.; Appl. Catal., A 2013, 456, 182.

13. Lotero, E.; Liu, Y.; Lopez, D. E.; Suwannakarn, K.; Bruce, D. A.; Goodwin, J. G.; Ind. Eng. Chem. Res. 2005, 44, 5353.

14. Caland, L. B.; Santos, L. S. S.; Moura, C. V. R.; Moura, E. M.; Catal. Lett. 2009, 128, 392.

15. Carvalho, L. M. G.; Abreu, W. C.; Silva, M. G. O.; Lima, J. R. O.; Oliveira, J. E.; Matos, J. M. E.; Moura, C. V. R.; Moura, E. M.; J. Braz. Chem. Soc. 2013, 24, 550.

16. Endalew, A. K.; Kiros, Y.; Zanzi, R.; Biomass Bioenergy 2011, 35,3787 . 
17. Semwal, S.; Arora, A. K.; Badoni, R. P.; Tuli, D. K.; Bioresour. Technol. 2011, 102, 2151.

18. Wei, Z.; Xu, C.; Li, B.; Bioresour. Technol. 2009, 100, 2883.

19. Li, M.; Zheng, Y.; Chen, Y.; Zhu, X.; Bioresour. Technol. 2014, $154,345$.

20. Kim, H.; Kang, B.; Kim, M.; Park, Y. M.; Kim, D.; Lee, J.; Lee, K.; Catal. Today 2004, 93, 315.

21. Wu, H.; Zhang, J.; Wei, Q.; Zheng, J.; Zhang, J.; Fuel Process. Technol. 2013, 109, 13.

22. Hipólito, P. H.; Castillejos, M. G.; Klimova, E. M.; Flores, N. J.; Cortés, A. G.; Klimova, T. E.; Catal. Today 2014, 220, 4.

23. Zabeti, M.; Daud, W. M. A. W.; Aroua, M. K.; Fuel Process. Technol. 2009, 90, 770 .

24. Behnajady, M. A.; Bimeghdar, S.; Chem. Eng. J. 2014, 239, 105.

25. Taufiq-Yap, Y. H.; Lee, H. V.; Yunus, R.; Juan, J. C.; Chem. Eng. J. 2011, 178, 342.

26. de Moura, C. V. R.; Neres, H. L. S.; de Lima, M. G.; de Moura, E. M.; Moita Neto, J. M.; de Oliveira, J. E.; Lima, J. R. O.; Sttolin, I. M.; Araújo, E. C. E.; J. Braz. Chem. Soc. 2016, 27, 515.

27. Torres, N. S.; Ibarra, I. C. R.; Pfeiffer, H.; Fuel Process. Technol. 2014, 120, 34.

28. Morais, M.; Pinto, L. A. A.; Ortiz, S. C. A.; Crexi, V. T.; da Silva, R. L.; da Silva, J. D.; Rev. Inst. Adolfo Lutz 2001, 60, 23.

29. de Galvão, L. P. F.; Barbosa, M. N.; Araujo, A. S.; Fernandes Jr., V. J.; Santos, A. G. D.; Luz Jr., G. E.; Quim. Nova 2012, 35, 41.

30. EN 14103:2003: Fatty Acid Methyl Esters (FAME), Determination of Ester and Linolenic Acid Methyl Esters Contents, European Committee for Standardization: Brussels, 2003.

31. JCPDS International Centre for Diffraction Data (JCPDS-ICDD 2001), No. 65-6920; Nakahigashi, K.; Shimomura, Y.; Fukuoka, N.; Acta Crystallogr., Sect. A 1972, 28A, 234.

32. JCPDS International Centre for Diffraction Data (JCPDS-ICDD 2001), No. 27-1304; Liu, B.; J. Geophys. Res. 1973, 78, 8470.
33. JCPDS International Centre for Diffraction Data (JCPDSICDD), No. 52-1526; Lin, C.; Liu, L.; Phys. Chem. Miner. 1997, 149.

34. JCPDS International Centre for Diffraction Data (JCPDSICDD) No. 19-1276; Mercer, M.; J. Inorg. Nucl. Chem. 1966, 61.

35. L'vov, B. V.; Thermochim. Acta 1997, 303, 161.

36. Niasari, M. S.; Davar, F.; Fereshteh, Z.; J. Alloys Compd. 2010 , $494,410$.

37. Abdelghany, A. M.; Elbatal, H. A.; J. Non-Cryst. Solids 2013 , $379,214$.

38. Bacce, E. D.; Pires, A. M.; Davalos, M. R.; Jafelicci, M.; Int. J. Inorg. Mater. 2001, 3, 443.

39. http://iaea.org/inis/collection/NCLCollectionStore/_ Public/42/105/42105302.pdf, accessed in June 2016.

40. Joint Committee for Guides in Metrology (JCGM/WG 1); Evaluation of Measurement Data, Guide to the Expression of Uncertainty in Measurement; 1995.

41. Abbaszaadeh, A.; Ghobadian, B.; Omidkhah, M. R.; Najafi, G.; Energy Convers. Manage. 2012, 63, 138.

42. Ramadhas, A. S.; Jayaraj, S.; Muraleedharan, C.; Fuel 2005, 84, 335.

43. Koh, M. Y.; Ghazi, M. T. I.; Renewable Sustainable Energy Rev. 2014, 15, 2011.

44. Yu, X.; Wen, Z.; Li, H.; Tu, S. T.; Yan, J.; Fuel 2011, 90, 1868.

45. Leung, D. Y. C.; Guo, Y.; Fuel Process. Technol. 2006, 87, 883.

46. Cruz, A. E. B.; Banda, J. A. M.; Mendoza, H.; Galvan, C. E. R.; Melo, M. A. M.; Esquivel, D.; Catal. Today 2011, 166, 111.

47. Silva, M. G. O.; Moura, C. V. R.; Moura, E. M.; Br 1.020.012.018.304-2, 2016.

Submitted: February 26, 2016

Published online: June 13, 2016

FAPESP has sponsored the publication of this article. 